\title{
Frontalis Sling Operation using Silicone Rod Compared with Autogenous Fascia Lata for Simple Congenital Ptosis
}

Purnima Rajkarnikar Sthapit, ${ }^{1}$ Rohit Saiju, ${ }^{2}$ Ben Limbu ${ }^{2}$

'Department of Ophthalmology, Dhulikhel Hospital, Kathmandu University School of Medical Sciences, Dhulikhel, ${ }^{2}$ Tilganga Institute of Opthalmology, Kathmandu, Nepal.

\section{ABSTRACT}

Introduction: To evaluate the cosmetic results and recurrence of unilateral frontalis sling surgery using a silicone rod compared with autogenous fascia lata in cases of simple congenital ptosis.

Methods: This is a retrospective comparative study of 59 patients who underwent a frontalis sling operation for congenital ptosis. Patients were divided into two groups according to the sling material used; an autogeneous fascia lata $(\mathrm{fl})$ group $(\mathrm{n}=24)$ and a silicone rod group (sl) ( $n=35$ ). Cosmetic results and recurrence rates were compared between these 2 groups. The cosmetic results of the frontalis sling operation were assessed as good, fair, or poor based on the difference between the Margin Reflex Distance (MRD) of both eyelids and graded as good if the difference in two eyes was $\leq 1 \mathrm{~mm}$ and poor if it was $2 \mathrm{~mm}$ or more. Recurrence was defined as the conversion of the cosmetic result from good or fair to poor category.

Results: At postoperative day seven and 30, MRD of both the groups were good but on three months follow-up MRD of silicon rod group dropped, however it was not statistically significant .Lid contour was good in both the groups, however, lid symmetry was poor in two cases of fascia lata at three months follow-up. Repeat surgery for poor outcome was done in $8.6 \%$ of cases in silicon rod and $8.3 \%$ of fascia lata group.

Conclusions: The frontalis sling operation using either a silicone rod or autogenous fascia lata showed equally good cosmetic results and lower recurrence rate at three months follow up.

Keywords: congenital ptosis; fascia lata; frontalis sling surgery; margin reflex distance; silicone rod.

\section{INTRODUCTION}

Congenital ptosis is abnormally low position of upper eyelid frequently occurs due to myopathy of levator palpebrae superiosis muscle. It has a characteristic feature of absent lid crease and higher lid height on down gaze than on normal side. ${ }^{1}$ It is frequently associated with superior rectus weakness due to its embryological association with the levator muscle. ${ }^{2}$

Surgery for ptosis correction is indicated when a ptotic eyelid blocks the visual axis causing amblyopia or for cosmetic purpose. Suspension of upper eyelid to frontalis muscle in forehead is the most common surgery performed for congenital ptosis with very poor levator function. The frontalis sling procedure is done

Correspondence: Dr. Purnima Rajkarnikar Sthapit, Department of Ophthalmology, Dhulikhel Hospital, Kathmandu University School of Medical Sciences. Dhulikhel, Nepal. Email : purnimark@gmail.com, Phone No : +977-9813254962 
Sthapit Frontalis sling operation using silicone rod compared with autogenous fascia lata for simple congenital ptosis.

by Fox's pentagon or Crawford double triangle method. Various materials like

autologus (AFL) and preserved fascia lata, synthetic materials like silicone rod, nylon, polyester and polytetrafluoroethylene are used as suspension material. ${ }^{3}$

The objective of the study is to evaluate the cosmetic results and recurrence of frontalis sling surgery using a silicone rod compared with those of AFL in simple congenital ptosis.

\section{METHODS}

It is a retrospective study of all the patients who underwent ptosis correction by frontalis sling surgery from $2004 A D$ to $2013 A D$ at Tilganga Institute of Ophthalmology, Kathmandu, Nepal. Autologus fascia lata was used as suspension material from 2004 to 2008. After that, Silicon rod is being used. Among those patients, we excluded patients with Marcus Gunn Jaw winking phenomenon, Blepharophimois and superior elevator palsy. Ethical approval has been taken from Institutional Research Committee for this study. Only patients with simple congenital ptosis who underwent frontalis sling surgery were included. We found 59 eyelids meeting above criteria which underwent the surgery. Among them, six patients had undergone bilateral surgery. Patients were divided into two groups according to the sling material used; a fascia lata group ( $\mathrm{fl} \mathrm{n}=24$ ) and a silicone rod group ( $\mathrm{sln}=35$ ).

Main outcome measures were reported in terms of Postoperative cosmetic results, complications and recurrence rate.

Financial Disclosures - The authors have no proprietary or commercial interest in any of the materials discussed in this article.

A complete ocular examination was performed preoperatively which included visual acuity, extraocular movements, slitlamp biomicroscopy and funduscopy. The amount of ptosis, upper eyelid margin reflex distance (MRD), levator function, jaw-winking phenomenon,orbicularis oculi strength and Bell's phenomenon were also evaluated. The amount of ptosis was defined as the difference between the MRD of the affected eyelid and the MRD of the contralateral normal eyelid in unilateral cases. For bilateral cases, it was estimated as the MRD minus $3 \mathrm{~mm}$ assuming the MRD of the normal eyelid is $3 \mathrm{~mm}$. Therefore MRD of two, one and less than $1 \mathrm{~mm}$ were graded as mild, moderate and severe ptosis respectively. ${ }^{1}$

\section{Surgical Techniques}

Autogeneous fascia lata brow suspension.

Harvesting fascia- a longitudinal incision made on lateral aspect of thigh in a line between lateral condyl of tibia and anterior superior iliac spine starting two inches above the knee extending upward 1.5 inches. Fascia lata is identified and is separated from subcutaneous tissue. Two longitudinal parallel incisions are made at the lower end of the exposed fascia. One blade passed through the incision and separator is pushed up the leg up to $12 \mathrm{~cm}$, cutting the fascia free on one side and also on anterior and posterior surfaces. The separator is brought down, turned over, passed through the outer incision in the fascia. After freeing the tissues, the lower end of the fascia is cut off and passed through the fascia stripper, cutting off the upper end. The fascia is spread out on board and secured with pins and cut into 2-3 mm wide strips using no. 15 surgical blade. ${ }^{1}$

Fascia lata brow suspension- Crawford method ${ }^{2}$

Six short incisions, $3 \mathrm{~mm}$ wide are placed over upper eyelid and forehead. The incisions over the lid are put $3 \mathrm{~mm}$ above the lid margin and just below the desired lid crease height. The center one is made just nasal to the midpoint of upper lid. The nasal one just lateral to the line of punctum and the lateral one at equal distance from the first two. The two brow incisions are put immediately above the eyebrows little wide apart than the lid incisions. The final incision is put $2 \mathrm{~cm}$ above the brow to create an isosceles triangle. The fascial strip is threaded from both lateral lid incisions to the central lid incision using Wright's needle, keeping it in the supratarsal space. Then both ends of the lateral strip of fascia as well as the central one are pulled up to the lateral brow incision by passing it deep to the orbicularis down to the lid incision, thus forming two isosceles triangles. After trimming one of the ends of the fascia lata in each brow incision, the other ends are pulled up to the central forehead incision. The desired lid height is estimated and fascia strip is tied in knots at brow and forehead incision. All three knots are reinforced with $6 / 0$ vicryl sutures. The skin incisions at brow and forehead is closed with 6/0 vicryl. At the end Frost sutures are applied to protect the cornea below the dressing. ${ }^{2}$

\section{Silicon rod brow suspension}

It is done using Fox's Pentagon method. In contrast to Crawford method, the central lid incision is avoided and the silicon rod is passed from two lid incisions to brow and finally to forehead incision forming a pentagon. At the central forehead incision, the two ends of the rods are passed through the sleeve provided with the rods and they are buried deep in the forehead pocket. Rest of the procedure is similar to Crowford method 
described above ${ }^{2}$

\section{Post operative evaluation}

The follow up data of examinations done at seven days, 30 days and three months were collected. The MRD, eyelid height asymmetry, lid contour symmetry, lagophthalmos, corneal exposure, and other complications were recorded for each group. The lid height asymmetry was calculated as the difference between the MRD of both eyelids and graded as good if the difference in two eyes was $\leq 1 \mathrm{~mm}$ and poor if it was $2 \mathrm{~mm}$ or more.

\section{Statistical Analysis}

The two groups were compared with respect to age, preoperative MRD and levator function using the independent $t$ test. Gender and laterality were compared using Chi square test. The postoperative MRD was compared using the independent $t$ test. Post operative complications were assessed and described. Patients who had to undergo repeat surgery were recorded. Statistical analyses were performed using SPSS software v. 20. P<0.05 was considered statistically significant.

\section{RESULTS}

There were 59 eyes of 54 patients who underwent frontalis sling surgery for congenital ptosis. Among them, fascia lata was used in 24 eyes and silicon rod used in 35 eyes as a sling material. Age of patient at surgery varied from two to 24 years with mean age of around 14.27 years. Male and female ratio was similar in both the groups as shown in Table. 1. Left eye was more common in both the groups; however it was not statistically significant. The preoperative levator function was poor in both the groups (sl $3.46 \mathrm{~mm}$ and $\mathrm{fl} 3.63 \mathrm{~mm}$ ), along with severe grade of ptosis in both groups ( $\mathrm{sl}-1.46$ and $\mathrm{fl}-1.58$ ) making them the ideal patients for frontalis sling surgery.

At postoperative day seven, MRD with the mean of $4.04 \mathrm{~mm}$ seems to be better in silicon rod group than in the fascia lata group (mean MRD of $3.77 \pm 0.91 \mathrm{~mm}$ ) but the difference is not statistically significant when $t$ test is applied as shown in Table 2. But MRD seems to be better in fascia lata group at one month and three months follow up, however again it was statistically not significant.

On evaluating the cosmetic outcome at one month, lid contour was good in both the groups; however, lid symmetry was poor in two cases $(8.3 \%)$ of fascia lata group due to recurrence. At three months follow up, one patient $(2.9 \%)$ in silicon rod group had recurrent ptosis and one patient in fascia lata group had a lateral drooping. Rest of the patient in both the groups had good lid contour. Readjustment of silicon rod was done in two patients for recurrent ptosis and in one patient for overcorrection. Repeat surgery for poor outcome was done in two patients $(8.3 \%)$ of fascia lata group, in which fascia was replaced with $2 / 0$ prolene suture in one and silicon rod in another patient. All the patients did well after repeat surgery.

Other complications like lagophthalmos at day seven was seen in 10 patients in silicon rod and seven patients in fascia lata group. It was treated with frequent lubricating eye drops and lid squeezing exercises.

\section{DISCUSSION}

Congenital ptosis is caused by myopathy of levator muscle due to which they have poor levator function. Along with this and severe type of ptosis is an indication for frontalis sling surgery. A variety of allogenic and synthetic materials are used as sling. Autogenous fascia lata is commonly used allogenic material. It is difficult to harvest but has an advantage of comparably low rates of recurrence, extrusion, breakage and granuloma formation. Among synthetic materials, silicon rod is readily available but reports of recurrence, extrusion and granuloma formation are found in literature. ${ }^{7}$ In our study, in 24 patients, fascia lata was harvested and in 35 patients, silicon rod was used to suspend tarsal plate to frontalis muscle to correct congenital ptosis.

Though it is a congenital ptosis, age of patients varied from two years to as big as 24 years with a mean age of 14.27 years when they presented to us. Congenital ptosis cases are usually operated only after 3-5 years of age when their facial growth and maturation occurs and the child also becomes more cooperative, thus allowing better measurements preoperatively so that surgical outcome is optimum. But in severe unilateral ptosis, where there is risk of developing amblyopia, early surgical intervention is recommended. ${ }^{8}$

In our study, postoperatively, the MRD was better in fascia lata group $(4.04 \pm 0.62 \mathrm{~mm})$ than in silicon rod group $(3.77 \pm 0.91)$ at day 7 . After one month and three months, it was better in silicon rod group $(3.58 \pm 1.10 \mathrm{~mm}$ and $3.33 \pm 1.18 \mathrm{~mm})$ than in fascia lata group $(3.31 \pm 0.83 \mathrm{~mm}$ and $2.98 \pm 1.51 \mathrm{~mm})$. However these differences are not statistically significant when t-test is applied as shown in Table 2. Yoon JS and Lee SY also found excellent outcome in early postoperative period with fascia lata regarding lid contour, symmetry, and lid crease showed worsening outcome at 6 months after surgery which was statistically significant 
$(P<0.001) .^{9}$

Khan $A$ et al also reported significantly good cosmetic and functional results using fascia lata (93\%) as compared to silicone tube $(73 \%) .^{7}$

\begin{tabular}{|llll|}
\hline $\begin{array}{l}\text { Table 1. Demography and Descriptive } \\
\text { Ptosis measurement. }\end{array}$ & Statistics of \\
\hline & $\begin{array}{l}\text { Silicon rod } \\
\text { group ( } \mathrm{n} \\
=35)\end{array}$ & $\begin{array}{l}\text { Fascia Lata } \\
\text { group ( } \\
\mathrm{n}=24)\end{array}$ & $\mathrm{p}$-value \\
$\begin{array}{l}\text { Gender( } \\
\text { male: } \\
\text { female) }\end{array}$ & $17 / 18$ & $0.601^{*}$ \\
$\begin{array}{l}\text { Age } \\
\text { Left eye/ } \\
\text { right eye }\end{array}$ & $19 / 16$ & $13 / 11$ & \\
$\begin{array}{l}\text { Pre Op. } \\
\text { Levator } \\
\text { Function } \\
\text { (mm) }\end{array}$ & $3.46 \pm 1.36$ & $3.63 \pm 1.25$ & $0.631^{* *}$ \\
$\begin{array}{l}\text { Preo Op. } \\
\text { MRD }\end{array}$ & $-1.46 \pm 1.62$ & $-1.58 \pm 1.41$ & $0.758^{* *}$ \\
\hline
\end{tabular}

*Chisquare test applied, ** t-test applied

\begin{tabular}{|llll|}
\hline \multicolumn{4}{|c|}{ Table 2. Post Operative MRD measurements in $\mathbf{~ m m}}$. \\
\hline & Silicon rod & Fascia lata & p-value \\
& group & group & \\
MRD (7days) & $3.77 \pm 0.91$ & $4.04 \pm 0.62$ & $0.212^{* *}$ \\
MRD ( 30 days) & $3.58 \pm 1.10$ & $3.31 \pm 0.83$ & $0.867^{* *}$ \\
MRD (90 days) & $3.33 \pm 1.18$ & $2.98 \pm 1.51$ & $0.322^{* *}$ \\
\hline
\end{tabular}

$* *$ t-test applied

Crawford had reported that it was difficult to harvest fascia lata in patients younger than 3 years old and that would not be sufficient for the operation. ${ }^{6}$ But KB Lale and Leibovitch $I$ et al performed sling surgery with autogenous fascia lata in children less than 3 years old where they did not experience any problems while harvesting enough fascia lata and all the cases had good surgical outcome and concluded that the most successful material is autogenous fascia lata. ${ }^{10,11}$ In contrary to above studies, Chawala et al found no statistical significant difference in terms of functional and cosmetic success between autogenous fascia lata and silicon rod groups. Difference in recurrence in two groups is not statistically significant.However they found silicon rod beneficial for better post-operative lid lag and lagophthalmos owing to their elasticity. ${ }^{12}$

However in another study done by Lee MJ et al, comparing silicon rod with preserved fascia lata, they found significant difference between two groups. In unilateral cases, the postoperative MRD was higher in the silicone rod group than the PFL group at 6, 12, 24 , and 36 months postoperatively and also asymmetry was significantly smaller in the silicone rod group than the PFL group at $3,6,12,24$, and 36 months postoperatively $(\mathrm{P}=0.03, \mathrm{P}=0.01, \mathrm{P}=0.001, \mathrm{P}=$ 0.01 , and $P=0.001$, respectively. ${ }^{3}$

Ali $Z$ et al reports that frontalis suspension using silicon tube has good efficacy and an excellent safety profile. The results of frontalis suspension using silicon tube are comparable to fascia lata and superior to other non-autogenous materials. They only had $2.8 \%$ of recurrence with silicon rod due to slippage. ${ }^{13}$

Therefore there are various opinions regarding the use of fascia lata or silicon rod for frontalis sling surgery. In our study too the difference in outcome between the two are not statistically significant however it has a limitation that it is a retrospective study.

\begin{tabular}{|llllll|}
\hline \multicolumn{5}{|l|}{ Table 3. Post operative $\mathbf{3 0}$ days cosmetic outcome. } \\
\hline \multicolumn{5}{|c|}{ Lid symmetry } \\
Group & & Frequency & Percentage & Frequency & Percentage \\
Fascia lata & Good & 35 & 100 & 35 & 100 \\
& Good & 22 & 91.7 & 24 & 100 \\
\hline
\end{tabular}

Table 4. Post operative 3 months cosmetic outcome.

\begin{tabular}{|c|c|c|c|c|c|}
\hline \multirow[b]{2}{*}{ Group } & \multirow[b]{2}{*}{ Outcome } & \multicolumn{2}{|c|}{ Lid symmetry } & \multicolumn{2}{|l|}{ Lid contour } \\
\hline & & Frequency & Percentage & Frequency & Percentage \\
\hline \multirow[t]{2}{*}{ Silicon rod } & Good & 33 & 97.1 & 35 & 100 \\
\hline & Poor & 1 & 2.9 & & \\
\hline \multirow[t]{2}{*}{ Fascia Lata } & Good & 22 & 91.7 & 23 & 95.8 \\
\hline & Poor & 2 & 8.3 & 1 & 4.2 \\
\hline
\end{tabular}


Sthapit Frontalis sling operation using silicone rod compared with autogenous fascia lata for simple congenital ptosis.

\begin{tabular}{|llll|}
\hline \multicolumn{4}{|l|}{ Table 5. } \\
\hline Group & & Frequency & Percentage \\
Silicon rod & No & 32 & 91.4 \\
& Yes & 3 & 8.6 \\
Fascia lata & No & 22 & 91.7 \\
& Yes & 2 & 8.3 \\
\hline
\end{tabular}

\section{CONCLUSIONS}

Blepahroptosis surgery is one of the most common oculoplastic procedures; the aim of which is to clear the visual axis, reducing amblyopia in young patients and improving superior visual fields and good cosmesis in adult patients. The established treatment for congenital ptosis with poor levator function is frontalis sling suspension surgery. Silicone rod and autogenous fascia lata both showed equally good cosmetic results.
The differences in post operative lid height and lid contour is not statistically significant. Both had lower recurrence rate at three months follow up. Owing to the readily availability and easy readjustments in recurrent cases, frontalis sling surgery with silicon rod can be the procedure of choice for severe unilateral or bilateral ptosis with similar cosmetic and functional outcomes. However, only prospective randomized studies with longer time follow ups can give a more accurate conclusion in this regard.

\section{ACKNOWLEDGEMENTS}

I would like to thank Mr Kishore Khanal, Lecturer at Department of Community Medicine, Kathmandu University School of Medical Sciences for helping me out with the statistical analysis.

\section{REFERENCES}

1. Byron C. Smith. Ophthalmic Plastic and Reconstructive Surgery. Vol. 1.C.V. Mosby Company; 1987.

2. AG Tyers and JRO Collin. Color atlas of Ophthalmic plastic surgery. $3^{\text {rd }}$ Ed. Butterworth Heinemann Elsevier; 2008.

3. Lee MJ, Oh JY, Choung HK, Kim NJ, Sung MS, Khwarg SI. Frontalis sling operation using silicone rod compared with preserved fascia lata for congenital ptosis a three-year follow-up study. Ophthalmology. 2009 Jan;116(1):123-9.

4. Payr E. Plastik mittels freier Faszientransplantation bei Ptosis. Dtsch Med Wochenschr. 1909;35:822.(German)

5. Wright WW. The use of living sutures in the treatment of ptosis. Arch Ophthalmol. 1922;51:99-102.

6. Crawford JS. Repair of ptosis using frontalis muscles and fascia lata a 20-year review. Ophthalmic Surg. 1977;8:31-40.

7. Khan A, Majid O, Wani J. Fascia lata versus silicone sling frontalis suspension for correction of congenital blepharoptosis. Int J Med Sci Public Health 2014;3:700-703.

8. Y Takahashi, I Leibovitch, and H Kakizaki. Frontalis Suspension Surgery in Upper Eyelid Blepharoptosis. Open Ophthalmol J. 2010; 4: 91-97.
9. Yoon JS, Lee SY. Long-term functional and cosmetic outcomes after frontalis suspension using autogenous fascia lata for pediatriccongenital ptosis. Ophthalmology 2009 Jul;116(7):1405-14.

10. L K Bilgin and B Yeniad. The Long-Term Results of Frontalis Suspension Using Autogenous Fascia Lata in Children with Congenital Ptosis under 3 Years Old. Plast Surg Intl 2010;2010:609462.

11. Leibovitch I, Leibovitch L, Dray JP. Long-term results of frontalis suspension using autogenous fascia lata for congenital ptosis in children under 3 years of age. AJO 2003 Nov;136(5):866-71.

12. Chawala A, Mansuri G, Trivedi N. A comparative study of frontalis sling surgery for simple congenital ptosis: use of autogenous fascia lata compared with silicon rod. J Res Med Den Sci 2014;2(3):28-31.

13. Ali Z, Kazmi HS, bin Saleem MK, Shah AA. Silicon tube fron talis suspension in simple congenital blepharoptosis.J Ayub Med Coll Abbottabad 2011 Oct-Dec;23(4):30-3 